\title{
DIAGNÓSTICO DAS CONDIÇÕES DE SAÚDE DE TRABALHADORES ENVOLVIDOS NA ATIVIDADE EM EXTRAÇÃO MANUAL DE MADEIRA ${ }^{1}$
}

\author{
Emilia Pio da Silva², Rosângela Minardi Mitre Cotta ${ }^{2}$, Amaury Paulo de Souza $^{3}$, Luciano José \\ Minette $^{3}$ e Horjana Aparecida Navarro Fernandes Vieira ${ }^{4}$
}

\begin{abstract}
RESUMO - O objetivo deste trabalho foi diagnosticar as condições de saúde de trabalhadores florestais envolvidos na atividade de extração manual de madeira. O estudo foi desenvolvido em uma empresa prestadora de serviços na área florestal, com 12 trabalhadores que realizavam extração manual de madeira no mês de maio de 2006, correspondendo a $100 \%$ dos trabalhadores. Um questionário foi utilizado para o diagnóstico das condições de saúde dos indivíduos. Os dados foram analisados por meio do programa Epi Info, versão 3.3.2. Dos participantes do estudo, $100 \%$ eram do gênero masculino, 56\% eram solteiros, $100 \%$ possuíam primeiro grau incompleto e casa própria - com relação à autoavaliação do estado de saúde - e $67 \%$ afirmaram ter boa saúde. Ao término do trabalho foi possível concluir que os trabalhadores florestais estão expostos a precárias condições de saúde e vida
\end{abstract}

Palavras-chave: Saúde ocupacional, Colheita florestal e Percepção de saúde.

\section{HEALTH DIAGNOSIS OF FOREST WORKERS IN MANUAL WOOD EXTRACTION}

\begin{abstract}
The objective of this work was to investigate the diagnosis of the health of the involved forestry workers in the activity of manual wood extraction. The study was carried out with 12 workers of a forestry contractor which executed manual wood extraction in May, 2006. A questionnaire was used for the health diagnosis evaluation of the workers with the following variables: self-evaluation of the health state, monthly wage, dental health problems and factors that harm health, among others. The data had been analyzed by means of the program Epi Info, version 3.3.2. Of the participants of the study, 100\% were of the male gender, $56 \%$ were single, $100 \%$ hadn't finished the first school degree and they were also house owners. In terms of the self-evaluation of their health condition, $67 \%$ affirmed to have good health. At the end of the work, it was possible to conclude that the forest workers are subjected to precarious conditions of health and life.
\end{abstract}

Keywords: Occupational health, Logging and Health perception.

\section{INTRODUÇÃO}

O setor florestal brasileiro teve grande expansão a partir da década de 1990, merecendo lugar de destaque na economia do país. A modernização do setor e, principalmente, da colheita florestal não aboliu os casos de patologias ocupacionais, já que muitas atividades continuaram a ser exercidas sob condições adversas à saúde do trabalhador, como é o caso da extração manual de madeira, sobretudo em regiões montanhosas.
Na colheita florestal, a extração é a etapa responsável pela movimentação de madeira desde o local de corte até a estrada, ou carreador, ou pátio intermediário ou zona de processamento. A extração manual ainda é utilizada principalmente em regiões montanhosas, devido à impossibilidade de entrada de tratores e à falta de equipamentos adequados (SEIXAS, 2002). Por ser atividade de difícil execução, ela geralmente envolve mão de obra barata, ou seja, pessoas sem qualificação profissional, sem acesso a educação, que veem no trabalho a maneira de prover

\footnotetext{
${ }^{1}$ Recebido em 20.08.2007 e aceito para publicação em 02.03.2010.

${ }^{2}$ Programa de Pós-Graduação em Ciência Florestal da Universidade Federal de Viçosa - Brasil. E-mail: <emiliapiosilva@yahoo.com.br> .

${ }^{3}$ Universidade Federal de Pelotas, UFPEL, Brasil. E-mail: <amaury@ufv.br>e < minetti@ufv.br>.

${ }^{4}$ Universidade Estácio de Sá. E-mail: <horjana@ig.com>.
} 
o sustento da família. Assim, muitas vezes se submetem às condições ruins de trabalho, ocasionando precárias condições de saúde.

A Organização Pan-Americana da Saúde (1996) considera saúde em sua dimensão mais ampla e não apenas a ausência de doenças; O conceito de saúde abrange acesso a emprego, educação, moradia, saneamento básico, lazer, convívio social, ecossistema saudável e condições econômicas, entre outros.

As condições de saúde dos trabalhadores não podem ser avaliadas somente tendo como referência as consultas realizadas por meio dos médicos das empresas, sendo preciso conhecer as diferentes condições de vida às quais esses sujeitos estão expostos. O efeito não desejado do trabalho sobre a saúde pode ser silencioso, e a saúde precisa ser construída e mantida no trabalho (ASSUNÇÃO, 2003).

De acordo com Brant e Melo (2001) o trabalho pode estabelecer condição tanto para a saúde quanto para o adoecimento. Os trabalhadores florestais muitas vezes estão expostos a intempéries climáticas, poeira, ruído, vibração, manuseio de carga, animais peçonhentos, ausência de local apropriado para higiene e alimentação e baixa remuneração, ou seja, condições que dificultam a manutenção e a promoção da saúde.

A saúde do trabalhador pode ser considerada valioso bem individual, comunitário e do país, sendo de responsabilidade dos empregadores e empregados sua manutenção e promoção no ambiente de trabalho. A saúde ocupacional garante não só a saúde do trabalhador, mas a produtividade e qualidade da empresa, por isso a preocupação com a saúde dos empregados não se deve centrar apenas no local de trabalho, mas estenderse até a casa dessas pessoas. O conhecimento dos hábitos, das condições e estilos de vida das pessoas pode mitigar doenças, sejam estas ocupacionais ou não (ORGANIZAÇÃOPAN-AMERICANADASAÚDE, 1996).

Segundo Silva et al. (2003), as ações de atenção à saúde do trabalhador devem ser organizadas para que seja prestada assistência multiprofissional às vítimas de doenças ocupacionais e acidentes no trabalho, incluindo diagnóstico, tratamento, recuperação e reabilitação. Uma visão mais ampla do cuidado em saúde do trabalhador deve abarcar a prevenção das enfermidades e a promoção da saúde e não apenas atenção centrada num modelo médico medicamentoso.
Segundo Giatti e Barreto (2006), a percepção de saúde dos trabalhadores é considerada um dos determinantes de saúde, podendo auxiliar, ainda, na avaliação das condições de saúde de determinada população. A percepção de saúde é um indicador subjetivo, mas está diretamente relacionada com a utilização dos serviços de saúde, grau de escolaridade, renda per capita, idade, condição do domicílio, doença crônica e afastamento das atividades habituais.

Conhecer a percepção e situação da saúde dos trabalhadores facilita o processo de trabalho na área de saúde que deve conjugar interesses da coletividade e do indivíduo, para que realmente possa desenvolver valores como vida, democracia, equidade, saúde, solidariedade.

Nesse contexto, este estudo teve como objetivo central diagnosticar as condições de saúde de alguns trabalhadores florestais envolvidos na atividade de extração manual de madeira.

\section{MATERIAL E MÉTODOS}

\subsection{Local do estudo}

Este trabalho foi realizado em empresa prestadora de serviços na área florestal localizada no município de Guanhães, situado no distrito florestal do Vale do Rio Doce, a 240 km da capital do Estado de Minas Gerais, com as seguintes coordenadas geográficas: $18^{\circ} 48^{\prime} 45^{\prime \prime}$ latitude sul e $42^{\circ} 56^{\prime} 15^{\prime \prime}$ longitude oeste. A região possui relevo suave a fortemente ondulado, mas apresenta uma das melhores produtividades florestais de eucalipto do Estado de Minas (SOUZA et al., 2006).

\subsection{População de estudo}

A empresa escolhida para este estudo prestava serviços na área florestal a diversas companhias, sendo as atividades de colheita florestal e silvicultura suas principais áreas de atuação. A pesquisa foi realizada com 12 trabalhadores florestais envolvidos na atividade de extração manual de madeira, no mês de maio de 2006. Todos os participantes eram do sexo masculino, com idade média de 29 anos, mínima de 21 e máxima de 44 anos.

\subsection{Descrição da Atividade}

A atividade de extração manual é dependente do modo como foi realizada a derrubada das árvores. O operador de motosserra deve derrubar as árvores sempre 
no sentido de locação das curvas de nível, em que as folhas e ramos ficam depositados ao lado das toras, formando "ruas" limpas, que facilitavam o tombamento.

O trabalhador florestal iniciava o tombamento sempre na parte superior do terreno. Durante todo o deslocamento pelo talhão, para cumprir seu objetivo, que era fazer a madeira chegar à margem da estrada, ele poderia dar tombos nas toras, empurrar com as mãos ou os pés e arremessar com os membros superiores, sendo comum o trabalhador parar de tombar a madeira, para empilhar à margem da estrada. Desse modo, a madeira não ficava acumulada, não obstruía a passagem de veículos. Se fosse necessário retirar ramos ou puxar alguma tora, os operários utilizavam o machado como ferramenta de trabalho.

Os trabalhadores realizavam pausas para ingestão de água, bem como para realizar necessidades fisiológicas. O ciclo de trabalho como tombar e empilhar toras de madeira era repetido diversas vezes, durante o dia de serviço, até que o trabalhador cumprisse sua meta diária de $12 \mathrm{~m}^{3}$ de madeira (Figura 1 ).



Figura 1 - Ciclo de trabalho da atividade de extração manual. Figure 1 - Manual wood extraction working cycle.

\subsection{Coleta de dados}

Para análise da percepção de saúde dos trabalhadores florestais foram realizadas entrevistas individuais no local de trabalho, por meio de questionário elaborado pela equipe de pesquisadores, a partir de estudos encontrados na bibliografia aplicados por um único entrevistador devidamente treinado. As principais variáveis analisadas foram: percepção da própria saúde, serviço médico utilizado, plano de saúde, problemas dentários, fatores que prejudicam a saúde, acesso a saneamento básico, práticas de atividades físicas, tabagismo e etilismo.

\subsection{Análise estatística dos dados}

Para análise dos dados foi utilizado o Epi Info versão 3.3.2 (2005), que é um programa de banco de dados e software de estatística de domínio público para profissionais de saúde pública.

\section{RESULTADOS E DISCUSSÃO}

Com relação ao perfil dos trabalhadores florestais, $100 \%$ eram do sexo masculino, solteiros (56\%), 100\% tinham nível de instrução inferior ao $1^{\circ}$ grau completo e residiam em casa própria, possuíam carteira profissional assinada e salário mensal de $\mathrm{R} \$ 384,40$, o que equivale a US\$167,14, sendo o salário mínimo na época de R\$350,00.

No que diz respeito à percepção sobre a própria saúde, $67 \%$ dos trabalhadores consideravam sua saúde boa. Isso pode estar relacionado à percepção de saúde apenas como ausência de doença e não como algo mais amplo que envolve educação, salário digno, moradia, saneamento básico, acesso à água potável etc. (ALVES, 2003).

De acordo com Minayo-Gomez e Thedim-Costa (1997), a resistência dos indivíduos em aceitar seu estado de saúde como frágil está relacionada ao medo de perder o emprego, sua única garantia de sobrevivência, inibindo, assim, incisivas de reivindicação às instâncias responsáveis pela garantia da saúde no trabalho.

Nenhum dos trabalhadores entrevistados possuíam plano de saúde privado, sendo 78\% desses totalmente dependentes do Sistema Único de Saúde (SUS), e 22\% usavam serviço de saúde da empresa. Muitos dos trabalhadores desconheciam os serviços de saúde oferecidos pela empresa, e assim, acabavam não usufruindo os benefícios.

Revista Árvore, Viçosa-MG, v.34, n.3, p.561-565, 2010 
Entre os entrevistados, 68\% afirmaram não gastar nenhuma porcentagem do salário mensal com medicamentos receitados por um médico, no entanto o hábito de usar medicamentos sem prescrição médica foi observado em 79\% dos indivíduos entrevistados. Segundo a Associação Médica Brasileira (2001), a automedicação é prática muito comum do brasileiro, mas o fato de se poder adquirir medicamento sem prescrição não permite ao indivíduo usá-lo por indicação própria, na dose que lhe convém e na hora que achar conveniente. O uso indevido dos medicamentos pode causar danos importantes ao organismo como hiperplasias, aparecimento de microrganismos resistentes, alterações sanguíneas e até mesmo mascarar e retardar um diagnóstico médico.

Nos últimos 12 meses, 33\% dos trabalhadores fizeram apenas duas consultas médicas, 23\% uma consulta e $44 \%$ nenhuma consulta. Os especialistas procurados foram: clínico geral, médico do trabalho, neurologista e ortopedista, e $20 \%$ dos trabalhadores que procuraram o serviço médico no último ano não souberam informar qual a especialidade do médico. Nenhum dos entrevistados ficou internado nos últimos 12 meses.

Dos trabalhadores estudados, $100 \%$ afirmaram realizar higiene corporal todos os dias, embora todos apresentassem problemas dentários e 45\% desses, ausência de alguns dentes, 33\% disseram ter cáries; e 22\% eram desdentados. A higienização bucal diária poderia evitar problemas como cárie e perda de dentes, levando a crer que a higieni e desses trabalhadores não era efetiva. Segundo Unfer e Saliba (2000), as cáries e a perda dentária podem ser evitadas com ações de autocuidado e visitas ao dentista, destacando ainda a necessidade de se implantarem programas de saúde bucal nas unidades de saúde, procurando utilizar metodologias de educação como parte do processo de capacitação da população para melhorar sua saúde bucal.

Neste estudo, 67\% dos trabalhadores disseram sentir dor em alguma parte do corpo, e 33\% deles queixavam-se de dores na coluna e $34 \%$ nos membros inferiores. Segundo Souza et al. (2002), as queixas de dores, principalmente lombalgias, relatadas frequentemente pelos trabalhadores envolvidos na colheita florestal, estão relacionadas à adoção de posturas corporais incorretas e à movimentação de cargas durante a realização da atividade; tais situações são comuns observadas durante a realização deste estudo no dia a dia dos trabalhadores.
Do total de trabalhadores, 89\% ficavam expostos a fatores como poeira, chuva, sol, entre outros, o que pode prejudicar sua saúde durante o trabalho. Os demais não reconheciam esses fatores como prejudiciais a sua saúde. Não obstante $75 \%$ deles terem afirmado ser o manuseio de carga o fator responsável por danos à sua saúde, principalmente a coluna vertebral. Fiedler (1998) corroborou esses resultados e afirmou que, apesar de os trabalhadores levantarem as toras em equipes de dois, há grandes riscos de danos à coluna vertebral, podendo ocasionar compressão do disco vertebral e estiramento dos músculos e dos ligamentos.

Com relação ao saneamento básico, 68\% afirmaram ter acesso à rede de esgoto, coleta de lixo, água tratada e serviços de iluminação elétrica. A maior parte dos trabalhadores (89\%) habitava em casas construídas com produtos industrializados, e 78\% consideraram a sua alimentação adequada para manutenção da saúde. O preocupante é que existem, ainda, pessoas (11\%) que residem em habitações de chão batido, erguidas com barro e bambu, telhado de sapé. Outras (32\%) sequer têm acesso a saneamento básico. Reitera-se que esses determinantes são essenciais para a promoção da saúde, partindo do princípio de que saúde permite viver com qualidade de vida, incluindo trabalho, educação, cultura, moradia, lazer ecossistema sustentável, entre outras coisas (ALVES, 2003).

Este estudo evidenciou que 33\% das pessoas dormiam menos de 8 por noite, e elas afirmaram que o período de sono não era suficiente para se sentir descansado. Isso pode estar relacionado ao fato de que as áreas de trabalho são distantes do município onde reside a maioria dos trabalhadores, obrigando eles a acordar de madrugada para chegar ao local de trabalho. Pignati e Machado (2005) evidenciaram que, quanto mais as áreas de trabalho se afastam das sedes dos municípios, piores são as condições de salário, saúde e trabalho.

Com relação ao uso de álcool e fumo, $67 \%$ dos trabalhadores consumiam bebida alcoólica, e 23\% eram tabagistas. Estudos desenvolvidos pela Organização Pan-Americana da Saúde (2006) comprovaram que vícios como o tabagismo e o alcoolismo pioram a cada dia a saúde do indivíduo, obrigando-o o a agir contra o seu bem viver e preservação de sua saúde. E os estudos de Giatti e Barreto (2006) também demonstraram que a saúde do trabalhador é influenciada não só pelos comportamentos de riscos, como uso de cigarro e álcool, mas por fatores psicossociais e posição econômica. 
De acordo com os dados da pesquisa, 90\% dos trabalhadores afirmaram não ter sofrido acidentes no trabalho nessa empresa, e os equipamentos de proteção individual (EPIs) comumente encontrados foram: capacete, luva, perneira e bota.

\section{CONCLUSÃO}

Os resultados deste estudo apresentaram dados relevantes sobre a saúde dos trabalhadores florestais envolvidos na atividade de extração manual de madeira. Foi possível perceber que, mesmo os trabalhadores considerando sua saúde como boa e apresentando alguns condicionantes importantes para o estado de saúde, a atividade estudada pode estar causando impactos negativos sobre a saúde desses operários.

\section{AGRADECIMENTOS}

À Coordenação de Aperfeiçoamento de Pessoal de Nível Superior - CAPES, pela concessão da bolsa de estudos à primeira autora.

\section{REFERÊNCIAS}

ASSOCIAÇÃO MÉDICA BRASILEIRA. Revista da Associação Medica Brasileira Oct./ Dec. 2001, v.47, n.4, p.269-270.

ALVES, R. B. Vigilância em saúde do trabalhador e promoção da saúde: aproximações possíveis e desafios. Cadernos de Saúde Pública. v.19, p.319-322, 2003.

ASSUNÇÃO, A. A. Uma contribuição do debate sobre as relações saúde e trabalho. Revista de Ciência e Saúde Coletiva, v.8, n.4, p.1005-1018, 2003.

BRANT, L. C.; MELO, M. B. Promoção da saúde e trabalho: um desafio teórico e metodológico para a saúde do trabalhador. Revista Saúde em Debate, v.25, n.57, p.55-62, 2001.

COUTO, H. A. Ergonomia aplicada ao trabalho em 18 lições. Belo Horizonte: Ergo, 2002. 202p.

FIELDER, N. C. Análise de posturas e esforços despendidos em operações de colheita florestal no norte do estado da Bahia. 1998.103f. Tese (Doutorado em Ciência Florestal) - Universidade Federal de Viçosa, Viçosa, MG, 1998.
GIATTI, L.; BARRETO, S. M. Situação do indivíduo no mercado de trabalho e iniqüidade em saúde no Brasil. Revista de Saúde Pública, v.40, n.1, p.99-106, 2006.

MINAYO-GOMEZ, C.; THEDIM-COSTA, S. M. F. A construção do campo da saúde do trabalhador: percurso e dilemas. Cadernos de Saúde Pública. v.13, 1997.

ORGANIZAÇÂO PAN - AMERICANA DA SAÚDE. Disponível em: <www.opas.org.br/rh/ publicacoes/textos_apoio/pub06u1t3pdf $>$. Acesso em: 04 abr. 2006.

PIGNATI, W. A.; MACHADO, J. M. H. Riscos e agravos à saúde e à vida dos trabalhadores das indústrias madeireiras de Mato Grosso. Revista de Ciência \& Saúde Coletiva, v.10, n.4, p.961-973, 2005.

SEIXAS, F. Extração. In: MACHADO, C. C. Colheita florestal. Viçosa, MG: Universidade Federal de Viçosa, 2002. p.89-128.

SILVA, K. R.; SOUZA, A. P.; MINETTE, L. J. Avaliação do perfil de trabalhadores e das condições de trabalho em marcenarias no município de Viçosa - MG. Revista Árvore, Viçosa, v.26, n.6, p.769-775, 2002.

SILVA, Z. P.; JUNIOR, I. F. B.; SANT'ANA, M. C. Saúde do trabalhador no âmbito municipal.

Revista de São Paulo em Perspectiva, v.17, n.1, p.47-57, 2003.

SOUZA, M. J. H. et al. Disponibilidade hídrica do solo e produtividade do eucalipto em três regiões da bacia do Rio Doce. Revista Árvore, v.30, n.3, p.399-410, 2006.

SOUZA, A. P.; MINETTE, L. J. Ergonomia aplicada ao trabalho. In: MACHADO, C. C. Colheita florestal. Viçosa, MG: Universidade Federal de Viçosa, 2002. p.293-309.

UNFER, B.; SALIBA. O. Avaliação do conhecimento popular e práticas cotidianas em saúde bucal. Revista de Saúde Pública, v.34, n.2, p.190-195, 2000. 
